\title{
Commentary
}

\section{Correcting misconceptions about synaesthesia}

\author{
Devin Blair Terhune $^{\mathrm{a}, *}$, Nicolas Rothen ${ }^{\mathrm{b}}$, Roi Cohen Kadosh ${ }^{\mathrm{a}}$ \\ a Department of Experimental Psychology, University of Oxford, UK \\ ${ }^{\mathrm{b}}$ School of Psychology and Sackler Centre for Consciousness Science, University of Sussex, UK
}

\section{Introduction}

In the annals of cognitive neuroscience there are examples of fantastic memory abilities (e.g., Luria, 1968) that befuddle the vast majority of us with normal mnemonic skills. Although such feats have yet to be demonstrated in other species, extraordinary memory may not be unique to humans. One possible example comes from a study by Inoue and Matsuzawa (2007), which showed that following extensive training, a chimpanzee, Ayumu, displayed superior working memory than human volunteers. Recently, Humphrey (2012) hypothesized that Ayumu outperformed the human participants because he had synaesthesia, a condition in which a stimulus (an inducer) will involuntarily elicit an atypical ancillary experience (a concurrent) (e.g., graphemes eliciting color photisms) (Ward, 2013). Specifically, Humphrey posits that Ayumu spontaneously developed grapheme-colour synaesthesia through "crosscortical leakage" (p. 354) between the parietal cortex, which may support the storage of overlearned sequences, and adjacent colour-coding regions, during working memory training. Humphrey speculates that the synaesthetic associations elicited colour afterimages during training with numerals, and, in turn, facilitated superior performance. Here we challenge this hypothesis and argue that it makes a number of assumptions that are not supported by current research.

The first incorrect assumption of Humphrey's (2012) hypothesis is that Ayumu has a heightened propensity to develop graphemecolour synaesthesia, relative to humans, during training. He speculates: "Thus, the reason it occurs may be just that the propensity for this kind of cross-cortical leakage has not been curtailed - as it apparently has been in humans" (p. 354). The sole piece of evidence that Humphrey offers in support of the claim that chimpanzees can develop such associations is a study showing that they display pitch-luminance correspondences, which, the authors of the study argue, opens up the "possibility that the condition of synesthesia may exist in nonhuman animals as well" (Ludwig, Adachi, \& Matsuzawa, 2011, p. 20663). Humphrey maintains that because the chimpanzees display these correspondences, it "makes the hypothesis more plausible" (Humphrey, 2012, p. 354). Although the distinction between crossmodal correspondences

\footnotetext{
* Corresponding author. Address: Department of Experimental Psychology, University of Oxford, South Parks Road, Oxford OX1 3UD, UK.

E-mail address: devin.terhune@psy.ox.ac.uk (D.B. Terhune).
}

and synaesthesia is beyond the scope of the present work, pitchluminance correspondences are not a recognized form of synaesthesia (Deroy \& Spence, in press). However, the real problem with this line of argumentation is that pitch-luminance correspondences are highly prevalent in non-synaesthetes (e.g., Martino \& Marks, 1999). Indeed, chimpanzees and non-synaesthete human participants displayed comparably sized crossmodal congruency effects in the Ludwig et al. (2011) study. It follows that there is no evidence that Ayumu has a greater propensity to develop grapheme-colour synaesthesia than human volunteers, as assumed in Humphrey's (2012) hypothesis.

Humphrey's (2012) speculations about the role of training in the development of novel grapheme-color associations are similarly problematic. There is evidence that inducer-concurrent pairs are learned in synaesthetes (e.g., Witthoft \& Winawer, 2013), thereby implicating learning mechanisms in the development of synaesthetic associations. Grapheme-color associations can be trained in nonsynaesthete human volunteers through the repeated pairing of graphemes with colors (Cohen Kadosh et al., 2005; Meier \& Rothen, 2009). However, no such training programme has yet to successfully produce a physiological marker of synaesthesia. This is crucial because humans are widely known to display pitch-luminance correspondences (e.g., Martino \& Marks, 1999). Accordingly, in contrast with Humphrey's (2012) hypothesis, exhibiting pitch-luminance correspondences does not provide any evidence regarding the propensity to form synaesthetic associations during training. Perhaps the most crucial obstacle for Humphrey's proposal is that Ayumu's training did not involve colors so any digit-color associations that arose through training would have to be purely spontaneous, rendering this possibility even more improbable. This is indeed what Humphrey (2012) claims - synaesthesia spontaneously develops through cortical leakage because of excessive training. However, there is no evidence that excessive training with graphemes will give rise to "cross-cortical leakage", and, in turn synaesthesia. Rather, the available evidence indicates that synaesthesia has a genetic basis and that environmental stimuli shape the specific associations rather than induce them (Brang \& Ramachandran, 2011; Witthoft \& Winawer, 2013).

The last misconception that we want to address is Humphrey's (2012) position regarding the mnemonic benefits of synaesthesia. Humphrey writes that "there is already plenty of evidence from human synaesthetes that their colour associations can indeed aid recall" (p. 354). 
Synaesthetes do display a specific pattern of enhanced memory (Rothen, Meier, \& Ward, 2012) but the contention that this could support the working memory performance of Ayumu represents a selective reading of the literature. Humphrey cites a case study describing extraordinary mnemonic abilities in a synaesthete (Smilek, Dixon, Cudahy, \& Merikle, 2002), but such individuals are not representative of synaesthetes and seem to have developed their abilities through mechanisms independent of their synaesthesia, such as savantism (Bor, Billington, \& Baron-Cohen, 2007). Indeed, group studies, such as the two cited by Humphrey (Gross, Neargarder, Caldwell-Harris, \& Cronin-Golomb, 2011; Yaro \& Ward, 2007), have revealed that synaesthetes' mnemonic advantage over nonsynaesthetes is statistically robust, but by no means does it reach a level that would sufficiently support Ayumu's performance (Rothen et al., 2012). The cumulative evidence strongly indicates that synaesthesia is not responsible for Ayumu's mnemonic abilities.

Beyond the foregoing misconceptions, it should be noted that the claim of Ayumu's extraordinary working memory is itself not as solid as Humphrey maintains. The human volunteers in the Inoue and Matsuzawa (2007) study did not actually receive the same training as Ayumu. In a recent study, two human participants underwent the same training with the same task as Ayumu and both performed significantly better (93\% and $97 \%$ accuracy, respectively) than Ayumu (79\%) on the most difficult version of the working memory task (Cook \& Wilson, 2010). Thus, Ayumu does not actually display superior working memory than humans, nor does his performance warrant extraordinary explanations.

Although we do not want to discount the possibility of synesthesia in non-human animals, the foregoing review indicates that there is no evidence for Humphrey's (2012) hypothesis that Ayumu's strong working memory arises from him possessing synaesthesia.

\section{Acknowledgments}

We acknowledge the support of the Cogito Foundation (D.B.T.), the Holcim Foundation (N.R.), the Dr. Mortimer and Theresa Sackler Foundation (N.R.), and the Wellcome Trust (WT88378) (R.C.K.).

\section{References}

Bor, D., Billington, J., \& Baron-Cohen, S. (2007). Savant memory for digits in a case of synaesthesia and Asperger syndrome is related to hyperactivity in the lateral prefrontal cortex. Neurocase, 13, 311-319. http://dx.doi.org/10.1080/ 13554790701844945.

Brang, D., \& Ramachandran, V. S. (2011). Survival of the synesthesia gene: Why do people hear colors and taste words? PLoS Biology, 9, e1001205. http:// dx.doi.org/10.1371/journal.pbio.1001205.

Cohen Kadosh, R., Sagiv, N., Linden, D. E., Robertson, L. C., Elinger, G., \& Henik, A (2005). When blue is larger than red: Colors influence numerical cognition in synesthesia. Journal of Cognitive Neuroscience, 17, 1766-1773. http://dx.doi.org/ $10.1162 / 089892905774589181$.

Cook, P., \& Wilson, M. (2010). Do young chimpanzees have extraordinary working memory? Psychonomic Bulletin \& Review, 17, 599-600. http://dx.doi.org/ 10.3758/PBR.17.4.599.

Deroy, O., \& Spence, C. (in press). Why we are not all synesthetes (not even weakly so). Psychonomic Bulletin E Review. doi:10.3758/s13423-013-0387-2.

Gross, V. C., Neargarder, S., Caldwell-Harris, C. L., \& Cronin-Golomb, A. (2011). Superior encoding enhances recall in color-graphemic synesthesia. Perception, 40, 196-208. http://dx.doi.org/10.1068/p6647.

Humphrey, N. (2012). This chimp will kick your ass at memory games - but how the hell does he do it? Trends in Cognitive Sciences, 16, 353-355. http://dx.doi.org/ 10.1016/j.tics.2012.05.002.

Inoue, S., \& Matsuzawa, T. (2007). Working memory of numerals in chimpanzees. Current Biology, 17, R1004-1005. http://dx.doi.org/10.1016/j.cub.2007.10.027.

Ludwig, V. U., Adachi, I., \& Matsuzawa, T. (2011). Visuoauditory mappings between high luminance and high pitch are shared by chimpanzees (Pan troglodytes) and humans. Proceedings of the National Academy of Sciences of the United States of America, 108, 20661-20665. http://dx.doi.org/10.1073/pnas.1112605108.

Luria, A. R. (1968). The mind of a mnemonist. Cambridge, MA: Harvard University Press.

Martino, G., \& Marks, L. E. (1999). Perceptual and linguistic interactions in speeded classification: Tests of the semantic coding hypothesis. Perception, 28, 903-923.

Meier, B., \& Rothen, N. (2009). Training grapheme-colour associations produces a synaesthetic Stroop effect, but not a conditioned synaesthetic response.

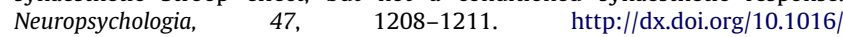
j.neuropsychologia.2009.01.009.

Rothen, N., Meier, B., \& Ward, J. (2012). Enhanced memory ability: Insights from synaesthesia. Neuroscience and Biobehavioral Reviews, 36, 1952-1963. http:// dx.doi.org/10.1016/j.neubiorev.2012.05.004.

Smilek, D., Dixon, M. J., Cudahy, C., \& Merikle, P. M. (2002). Synesthetic color experiences influence memory. Psychological Science, 13, 548-552.

Ward, J. (2013). Synesthesia. Annual Review of Psychology, 64, 49-75. http:// dx.doi.org/10.1146/annurev-psych-113011-143840.

Witthoft, N., \& Winawer, J. (2013). Learning, memory, and synesthesia. Psychological Science, 24, 258-265. http://dx.doi.org/10.1177/0956797612452573.

Yaro, C., \& Ward, J. (2007). Searching for Shereshevskii: What is superior about the memory of synaesthetes? Quarterly Journal of Experimental Psychology, 60, 681-695. 